\title{
MICROSTRUCTURE AND MECHANICAL PROPERTIES OF HOMOGENIZED STIR CASTING ALUMINUM BRONZE ALLOYS
}

\author{
Prof .Dr.Sami Abualnoun Ajeel \\ Department of Production Engineering \& Metallurgy, University of Technology, Baghdad, Iraq \\ samiabualnon2@yahoo.com \\ Asst. Prof. Dr. Rabiha S. Yaseen \\ Department of Production Engineering \& Metallurgy, University of Technology, Baghdad, Iraq \\ rabihazw@yahoo.com

\section{Asaad Kadhim Eqal} \\ Department of Production Engineering \& Metallurgy, University of Technology, Baghdad, Iraq \\ asaadka77@gmail.com
}

\begin{abstract}
In demand to the industrial needs to produce $\mathrm{Cu}-\mathrm{Al}$ alloys with controlled chemical compositions. The present research focuses on the production of $\mathrm{Cu}-\mathrm{Al}$ alloys with different aluminum additions of 1.9, 3.6, 5.8 and $7.7 \mathrm{wt}$. \% by stir casting method in argon atmosphere. Then, homogenized treatment was done for these alloys at $850^{\circ} \mathrm{C}$ in different periods of soaking time of 2 , 4 , and 6 hrs to determine the best conditions for increasing the mechanical properties. This is carried out in the a phase region. The microstructure of the samples is analyzed by using Optical and Scanning Electron Microscopy (SEM) with (EDS). The results showed the mechanical properties of copper were increased with increasing in Aluminum content. The microstructure of the castings consist of the dendiritic structure, columinar grains and segregation. The results showed that after homogenization, the microstructure changed to fine grains, elimination of the columnar segregation and the clusters disappeared. The XRD results show that the phases are $\alpha$ (Cu-rich) phase as highest peaks and the small amount of CuAl 2 phase. The best Aluminum content value was $7.7 \mathrm{wt} \%$ and the soaking time 4 hrs were given the high hardness $204 \mathrm{Hv}$ and the highest ultimate tensile stress value of $383.8 \mathrm{Mpa}$.
\end{abstract}

Keywords: Aluminum Bronze, Stir Casting, homogenization, soaking time, microhardness 


\section{INTRODUCTION}

Aluminum bronzes alloys, copper-based alloys with aluminum as the major alloying element, are of great interest because of its excellent physical and chemical properties, good corrosion resistance and low material cost [1]. These alloys are important for many industerial applications such as railway, aviation, and marine application. Also, other applications in which theses alloys are used for example the general water supply, oil and petrochemical industries, specialized anti-corrosive. The range of applications depends on the addition of $\mathrm{Al}$ element which is usually in the range of $5 \%-14 \%$ [2]. This leads to solid solution strengthening in the $\mathrm{Cu}-\mathrm{Al}$ alloy since the $\mathrm{Al}$ element increases dislocation density during the deformation twinning process [3,4]. Cu-Al alloy is produced by the casting process which is considered most economical method for obtaining a part of any desired composition, or by any size from a few millimeters. In order to achieve good hardness and mechanical properties, the eutectic $\mathrm{Cu}-\mathrm{Al}$ as intermetallic compound should be modified and heat treated. The production of $\mathrm{Cu}-\mathrm{Al}$ has been the subject of many investigations. These investigations, however, have focused on $\mathrm{Al}$ addition more than $9 \mathrm{wt} \%$ and in two phase region. For instance, Gupta et al. investigated the effect of solution treatment and aging on the hardness of $\mathrm{Cu}-9 \% \mathrm{Al}-6 \% \mathrm{Ni}$ $5 \% \mathrm{Fe}$ aluminum bronze. Increase in hardness of the alloy has been reported from $212 \mathrm{HB}$ to $362 \mathrm{HB}$ due to the formation of $\beta$ phase that is formed during quenching of solid solution and segregation of fine intermetallic in the aging process [5]. Similarly, Peter Salma, et al. investigated the influence of annealing, quenching, and aging on the microstructure and mechanical properties of the Cu10Al5Ni4Fe alloy. $\mathrm{He}$ compared his results with high-alloyed Cu14AI5Fe aluminum bronze, where the high hardness and wear resistance are imparted due to the $\beta+\gamma$ phases [6]. Abdul Hameed Khan et al. Has also found increased in hardness to $300 \mathrm{Hv}$ by aging at $300{ }^{\circ} \mathrm{C}$ at $2 \mathrm{hrs}$, and tensile stress became $620 \mathrm{Mpa}$. When he studied the production of aluminum bronze (Cu-10Al-3Fe alloy) [7]. Achiţei et al. used stir castings to produce Cu7Al3Mn aluminum bronzes. The researcher concluded improvement of the mechanical properties and hardness by heat treatment such as homogenization for 2 to 3 hours, quenching in water and tempering [8]. From above it is found that the mechanical properties of aluminum bronzes can be improved with heat treatments, that play an important role in controlling these properties and microstructural features of Al bronzes $[9,10]$. Many researchers have been used the $\mathrm{Cu}-\mathrm{Al}$ alloy with the addition of $10 \mathrm{wt} \%$ or more of Al content in the twophase region. Also, it is found lacking of studies that cover the study of (fcc $\alpha$-phase region) alloys. In the present work, the stir casting process and homogenization with various times are adopted to study the influence of Aluminum element addition with (fcc $\alpha$-phase region) alloys on microstructure and mechanical properties that are useful in the marine application 


\section{MATERIALS AND METHODS}

\subsection{Materials Used}

The materials that used in this work are pure copper and pure Aluminum analyzed by ICP-AES in IBN SINA FACTORY that listed in Table 1. The raw materials were cut to small pieces with dimensions of (20x20x20) $\mathrm{mm}$ in order to simplify melting materials in stir casting.

Table 1: the analytical chemical composition of the materials

\begin{tabular}{|l|l|l|l|l|l|l|l|l|}
\hline Alloy & $\mathrm{Cu}$ & $\mathrm{Al}$ & $\mathrm{Ag}$ & $\mathrm{Fe}$ & $\mathrm{P}$ & $\mathrm{Mn}$ & $\mathrm{Pb}$ & $\mathrm{Si}$ \\
\hline $\mathrm{Cu}$ & 99.78 & - & 0.127 & 0.05 & 0.046 & - & 0.001 & - \\
\hline $\mathrm{Al}$ & - & 99.811 & - & 0.047 & - & 0.073 & - & 0.033 \\
\hline
\end{tabular}

\subsection{Description Of Stir Casting Methods}

The stir casting is carried out by using system consisted of induction furnace, graphite crucible and drill with speed about 600 RPM by graphite impellers as shown in detail in Figure 1(a, b, d, and e). Cast iron mold is with two holes diameter $10 \mathrm{~mm}$ and $16 \mathrm{~mm}$ as shown in Figure 1 (b). The meseaured devises that used in this study were Optical Microscope (OM) observation, microhardness test using a Digital Micro Vickers Hardness tester TH714 of (300) g load, and XRD using a Shimdzu 6000 X-ray diffraction target CuKa1 radiation with $2 \theta$ angle covered from 15 to 120 degrees. Scanning electron microscopy (SEM) is used to investigate microstructures. Energy dispersive spectroscopy (EDS) is used to identify elements and other microstructural features.
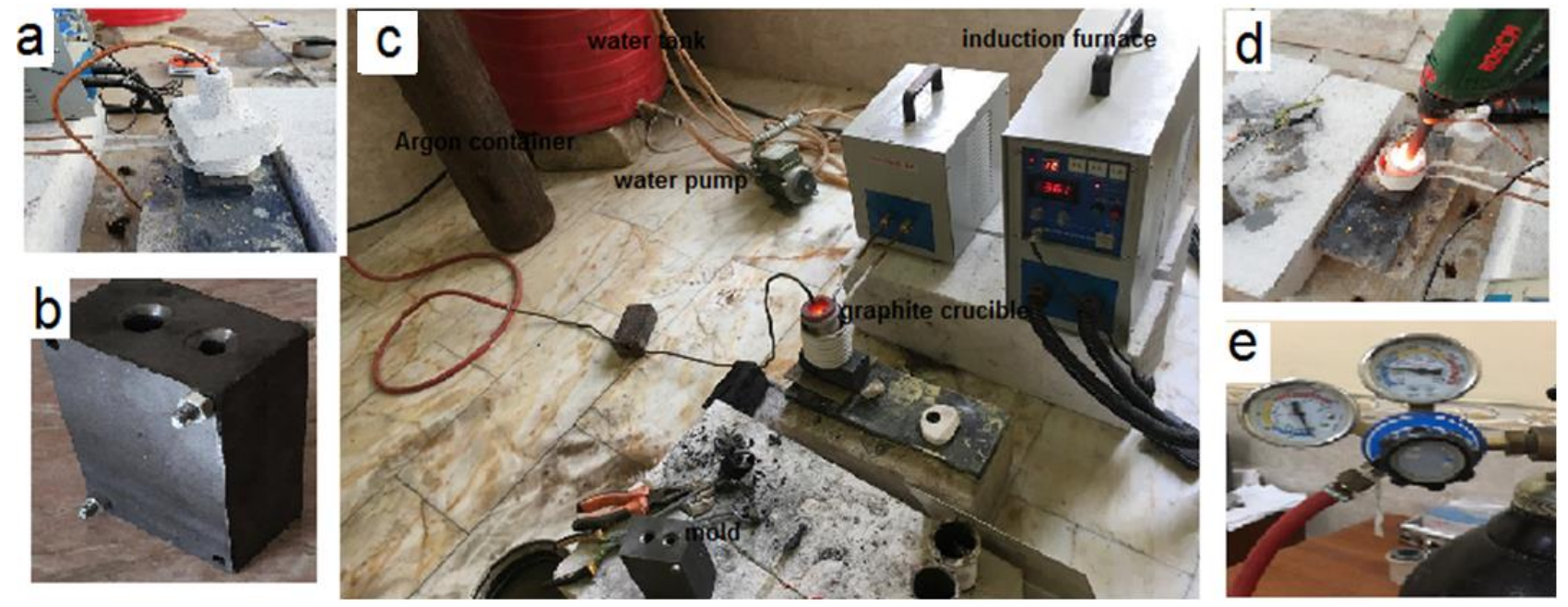

Figure 1: (a) Cup to inert gas, (b) Cast iron mold, (c) Stir casting system (d) Stirring with graphite crucible, (e) Argon container. 


\section{AL-QADISIYAH JOURNAL FOR ENGINEERING SCIENCES}

Vol. 11 , No. 2

ISSN: $1998-4456$

Infrared thermometer is used to measure the molten metal temperature and Heraeus HANAU furnace was used of the homogenization treatment with argon atmosphere as shown in Figure $2(a, b)$.
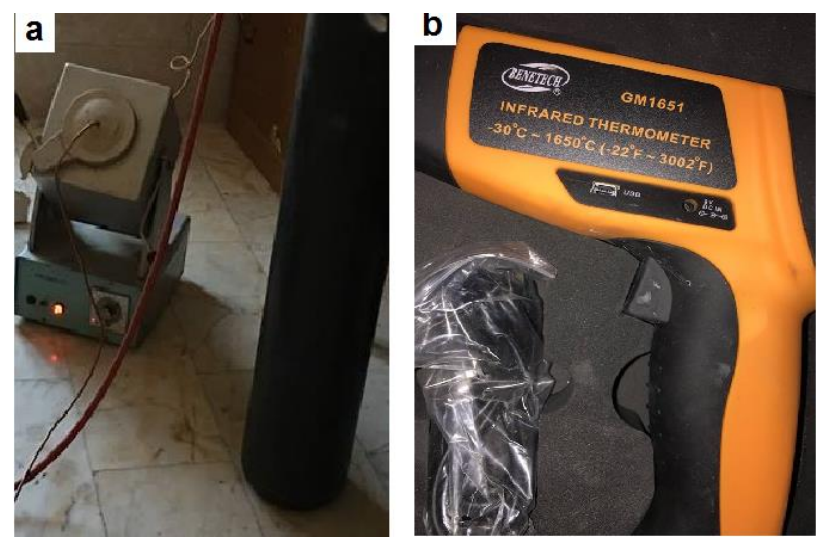

Figure 2: (a) Homogenization furnace, (b) Thermometer infrared.

\subsection{Plan Work And Proceduer of the Stir Casting}

The system of stir casting methods is used to melt material with a melting temperature at $1120{ }^{\circ} \mathrm{C}$. The process is started with the preparation of the charge containing the required quantities of elements $\mathrm{Cu}$ and Al. Stir casting method with argon atmosphere was used for producing the samples in this study. The preheat of casting molds for about $(100-150)^{\circ} \mathrm{C}$ before pouring is very important to minimize the casting defects such as shrinkage cavities [12]. The raw material was measured using the weighing balance with the accuracy of 0.001 . These elements are melted by the induction furnace, after five minutes, the melt was stirred vigorously to ensure the aluminum is dissolved in a crucible. The melt surface covered with fluxes are usually based on borax, due to the ability to dissolve and collect objectionable oxide and makes it possible to obtain a structure free from non-metallic solids.

\subsection{Effect of Heat Treatment Process on Alloys}

Homogenization is a process that used to remove the dendritic and coarse structure from the ingots, in addition reduction imbalanced distribution obtained during the solidification process. The heat treatment that used in this work is homogenization at $850^{\circ} \mathrm{C}$ at different soaking time of 2,4 , and 6 hours, followed by water-quenching for all casts to obtain structure homogenization. 


\subsection{Sample Preparation}

The diameter and the length of the ingots are $16 \mathrm{~mm}$ and $120 \mathrm{~mm}$, respectively. The ingots are cast as rods as shown in Figure 3 (a). These materials are cut to specimens with dimension $5 \mathrm{~mm}$ length and $16 \mathrm{~mm}$ diameter as shown in Figure 3 (b). The tensile test samples prepared using a turning machine according to ASTM E8M to identify mechanical properties as shown in Figure 3 (c). These samples are grinded, polished as shown in Figure 3 (b). In addition, etched by Keller reagent $\left(5 \mathrm{~g} \mathrm{FeCl}_{3}, 95 \mathrm{ml}\right.$ methanol, $5 \mathrm{ml} \mathrm{HCl}$ ) in order to reveal the microstructure and microhardness.

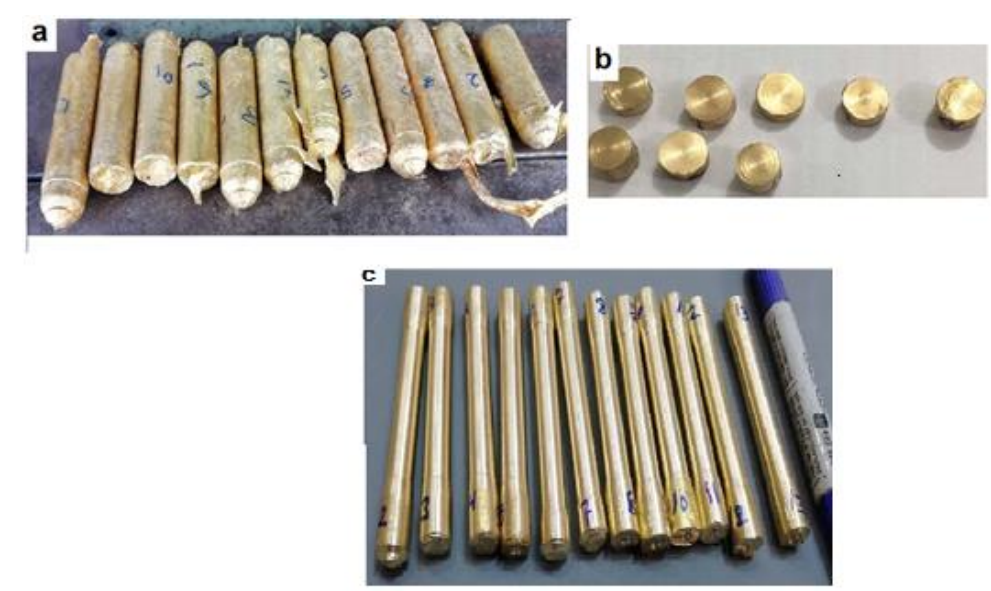

Figure 3: (a) The rod casts, (b) cutting rods to small sample and (c) Tensile test sample

\section{RESULTS AND DISCUSSION}

\subsection{Study of Al Addition on Microstructure}

The columnar (dendritic) microstructure of $\mathrm{\alpha}-\mathrm{Cu}$ in aluminum bronze alloy is noticed in the all untreated specimens that are produced by stir casting methods. During solidification in the cast iron mold, differences in composition between the melt and solid phase cause the distribution of the aluminum elements in the interior of the dendritic microstructure of copper. Figure (4) (a, b, c, and d) indicates the microstructure of as-cast of $\mathrm{Cu}-\mathrm{Al}$ alloys containg different amounts of aluminum which are examinned. The microstructure features have consisted mainly of crystals a solid solution with face-centered cubic lattice and the $\mathrm{CuAl}_{2}$ phase as intermetallic compound on the grain boundary or between dendrite arms [20]. The difference in the secondary dendrite arm spacing of $\alpha$-Cu solid solution and the size of eutectic $\mathrm{CuAl}_{2}$ with increased of $\mathrm{Al}$ additions from 3.6 to $8 \mathrm{wt} \% \mathrm{Al}$. This is because the copper lattice is able to dissolve a certain amount of atoms $\mathrm{Al}$ element. These atoms take the lattice sites of copper atoms which are called solid solutions strengthening [21]. All these phases are identified by XRD analysis as shown in Figure (8). 

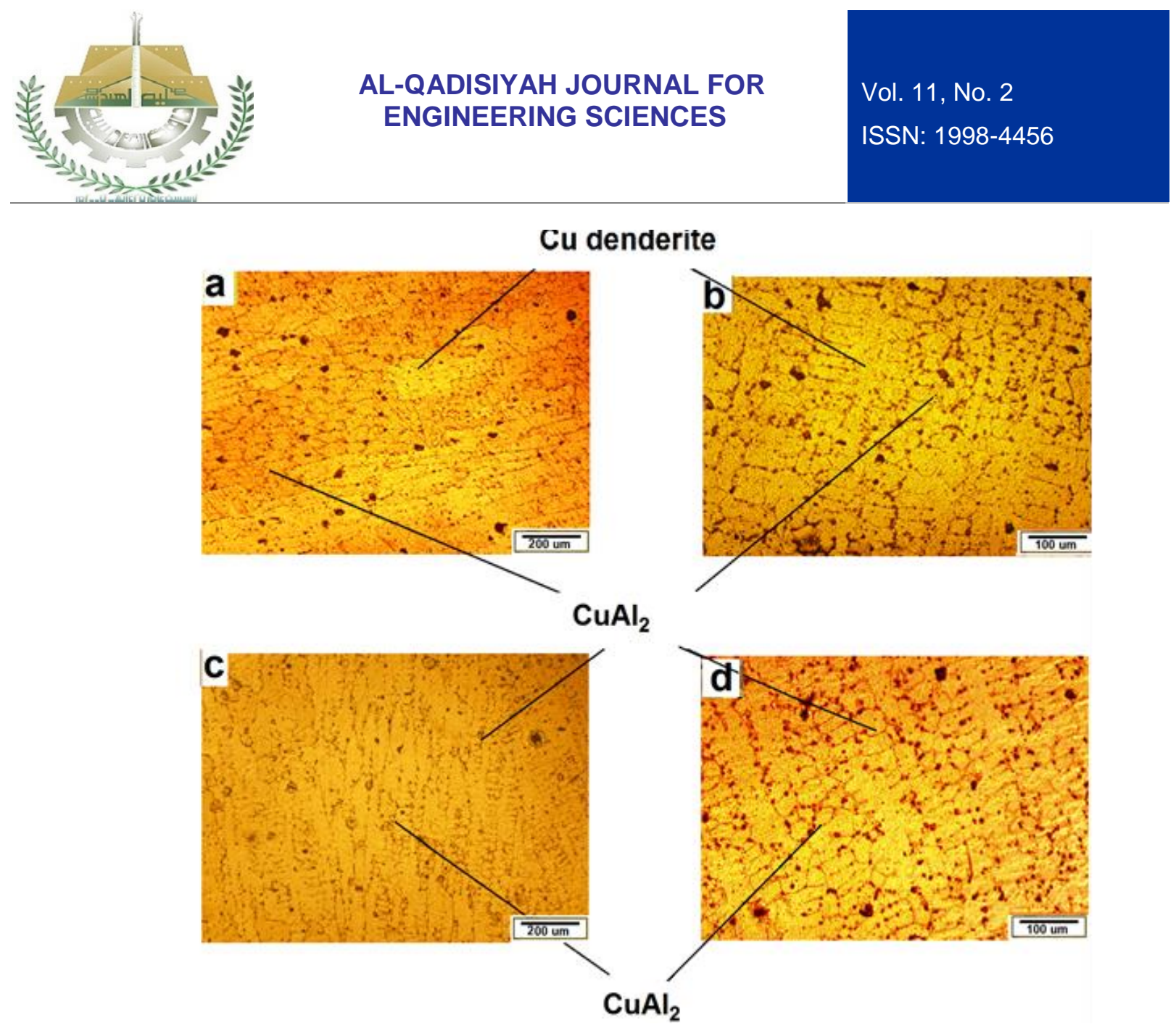

Figure 4: Optical microscope of $\mathrm{Cu}-\mathrm{Al}$ alloys shows the columnar and dendrite $\alpha$ phase solid solution as cast at magnification 100X and 200X, (a, b) Cu5.8Al, (c, d) Cu7.7Al.

\subsection{Study of Homogenization on Microhardness of Alloys}

Figure 5 ( $a, b, c$ and d) shows the equiaxed grains in the microstructure of these specimens that homogenized at $850{ }^{\circ} \mathrm{C}$ for 2,4 and 6 hrs due to relieve the cast structures and the elimination of the dendrite structure [19]. The analysis of the results shows that the hardness tends to increase with increasing the aluminum content, as well as the hardness will also increase with increasing the time of soaking for the homogenization. Figure 6 . Show that the best hardness value is obained at the soaking time of $4 \mathrm{hrs}$. It is obvious that the hardness of the samples increases as the Al content increased. The hardness of the sample in $4 \mathrm{hrs}$ increased from $76 \mathrm{Hv}$ to $204 \mathrm{Hv}$ after the homogenization process at $850{ }^{\circ} \mathrm{C}$ when the aluminum content increase from 1.9 to $7.7 \mathrm{wt} \%$. This is due to the differences in composition are equalized in some alloys by long-time homogenization as a result of diffusion processes taking place in the solid phase [16]. In addition, the change in the dendrite structure to equiaxed grain has occurred during the homogenization process $[17,18]$. 


\section{AL-QADISIYAH JOURNAL FOR ENGINEERING SCIENCES}

Vol. 11, No. 2

ISSN: $1998-4456$
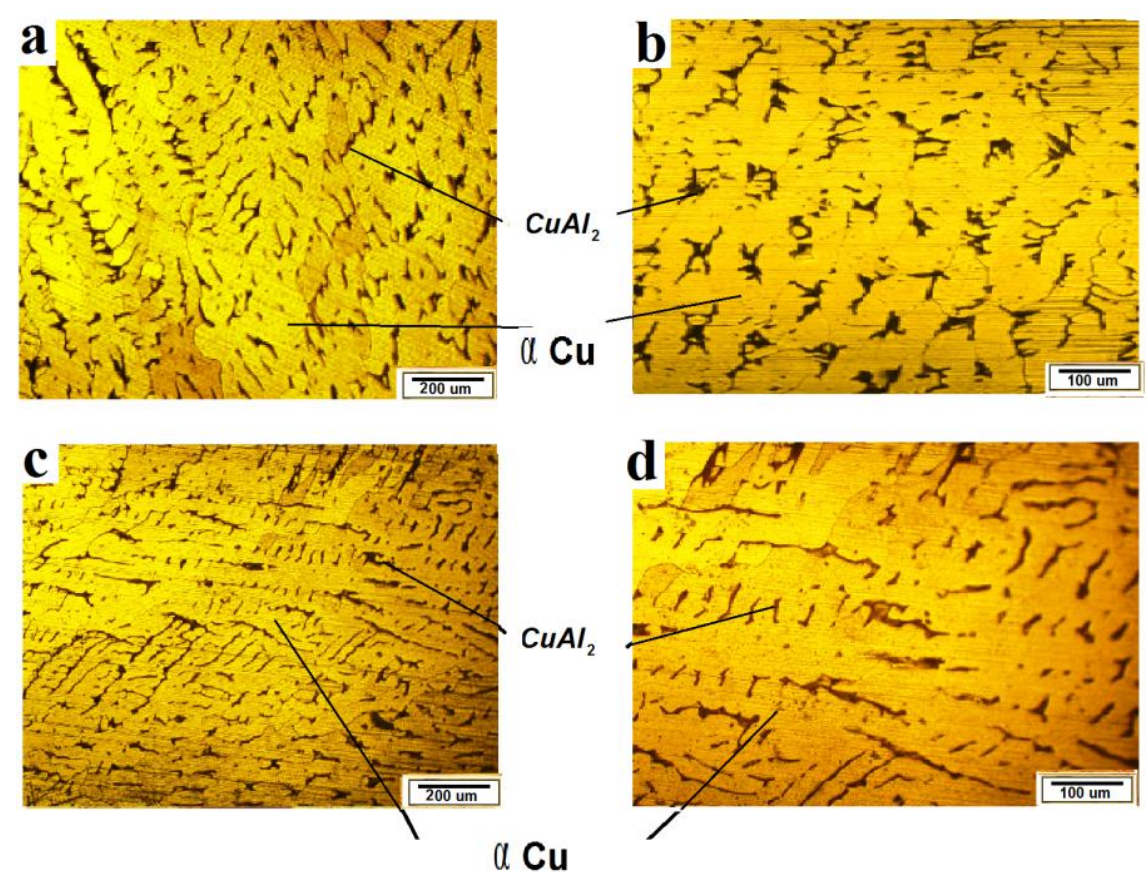

Figure 5: Optical microscope of Cu-Al alloys (a, b) Cu5.8Al and (c, d) Cu7.7Al, shows the equiaxed grain after homogenization $850 \mathrm{C}$ for $4 \mathrm{hrs}$ at magnification 100X and 200X.

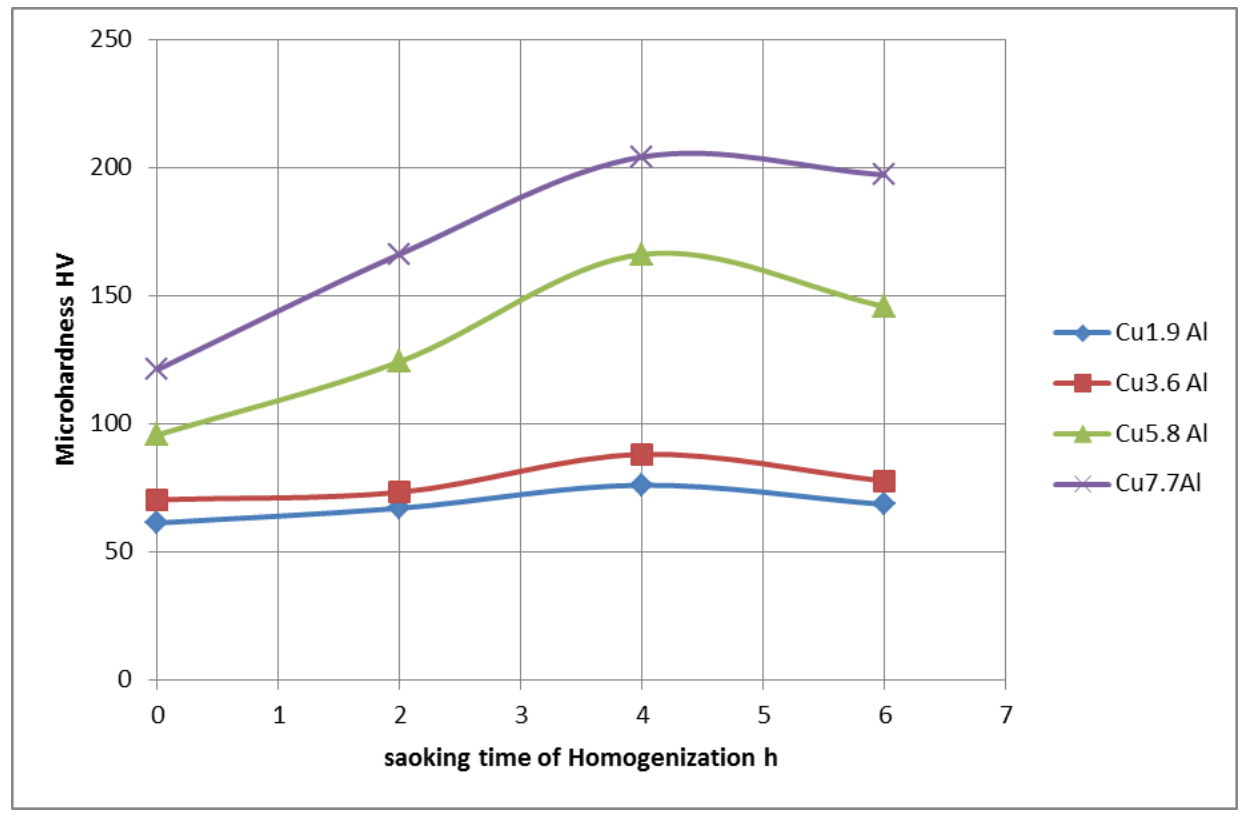

Figure 6: Micro hardness of Cu-Al alloys at different soaking time of homogenization at $850{ }^{\circ} \mathrm{C}$.

The SEM images in Figure 7( $a$ and $b$ ) of Cu-Al alloy show lower amount of defect of porosity and inclusion in microstructures of homogenized specimens at $850^{\circ} \mathrm{C}$ for $4 \mathrm{hrs}$. EDS analysis for $7.7 \%$ wt Al of aluminum 


\section{AL-QADISIYAH JOURNAL FOR ENGINEERING SCIENCES}

Vol. 11, No. 2

ISSN: 1998-4456

bronze alloy specimen is expected to contain more dissolved Aluminum as solid solution in the copper matrix as shown in Figure $7(\mathrm{c}$ and $\mathrm{d})$.
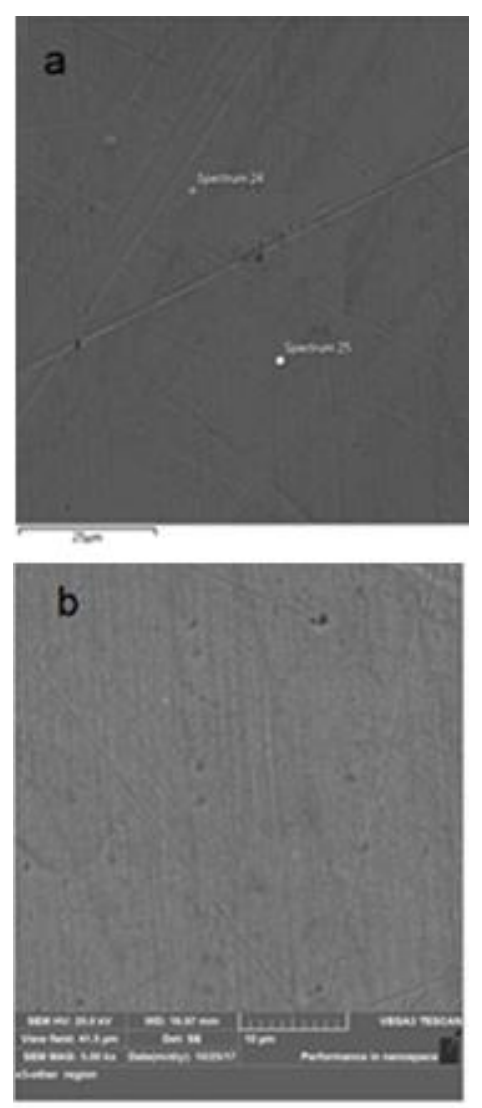
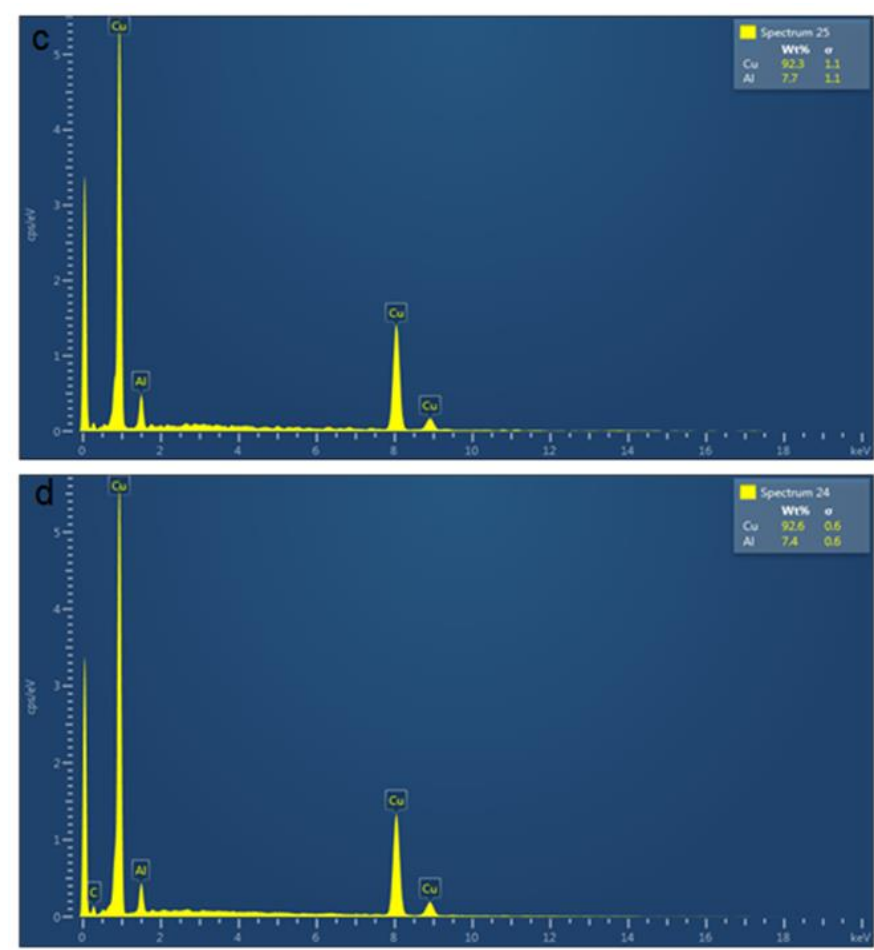

Figure 7: Microstructure of Cu-Al alloy ( $\mathrm{a}$ and b) SEM images of Cu7.7Al and (c and d ) EDS of Cu Al alloy that homogenized at $850^{\circ} \mathrm{C}$ for $4 \mathrm{hrs}$.

Intermetallic phase of the cast alloy is determined by XRD using CuKa1 radiation. The $2 \theta$ angle covered is from 15 to 100 degree. XRD analysis is performed in the specimens showing strong peaks of the $\mathrm{Cu}$-rich a phase. The smallest peaks of the eutectic $\mathrm{CuAl}_{2}$ phase as intermetallic compound that formed in the matrix as shown in Figure 8. 


\section{AL-QADISIYAH JOURNAL FOR ENGINEERING SCIENCES}

Vol. 11, No. 2

ISSN: $1998-4456$

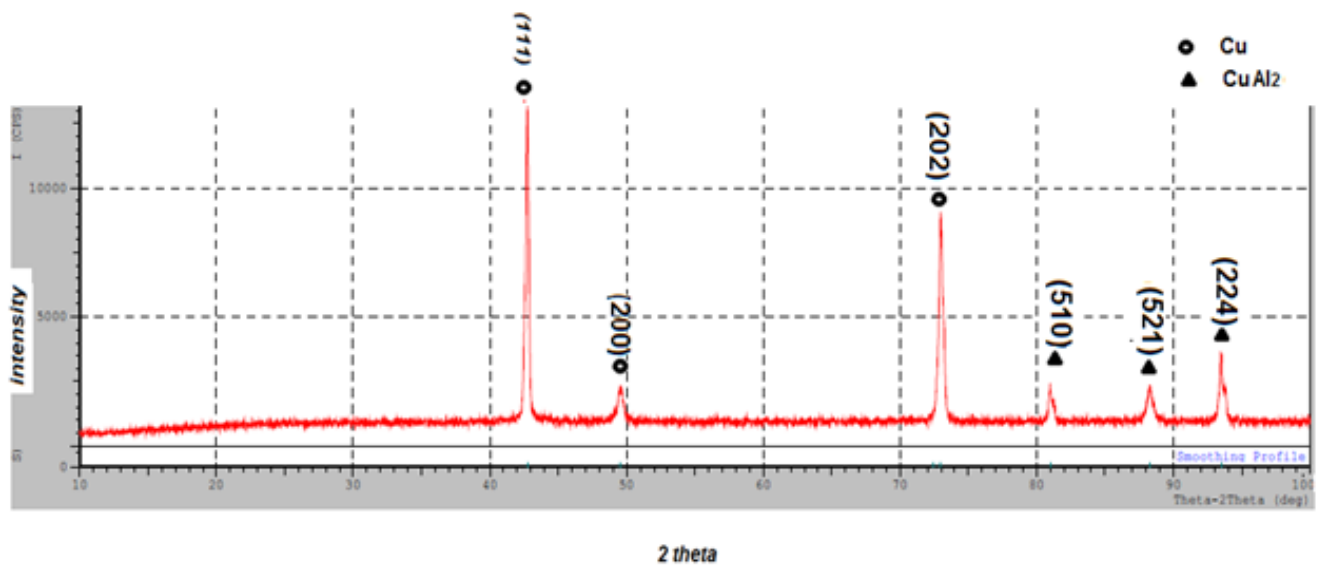

Figure 8: Shows XRD using Cu Ka radiation peaks of $\mathrm{Cu}-\mathrm{Al}$ alloy, homogenized $850^{\circ} \mathrm{C}$ for 4 hours.

\subsection{TENSILE TEST}

Figures 10 represents the stress-strain diagram for all samples that homogenized at $850^{\circ} \mathrm{C}$ for $4 \mathrm{hrs}$ soaking time. It explains a significant increase in ultimate tensile and yield strengths with increase $\mathrm{Al}$ content. In this figure, when the Al content increased from 1.9 to $7.7 \mathrm{wt} \%$ the ultimate tensile and yield strengths change from 175 Mpa to 383.8 Mpa and 38.97 Mpa to $175.38 \mathrm{Mpa}$ respectively. In addition was observed the increase in hardness from $48.67 \mathrm{Hv}$ to $204.13 \mathrm{Hv}$ with an increase in Al content as shown in Figure (11). The high strength and hardness accompanied by an increase in strain.

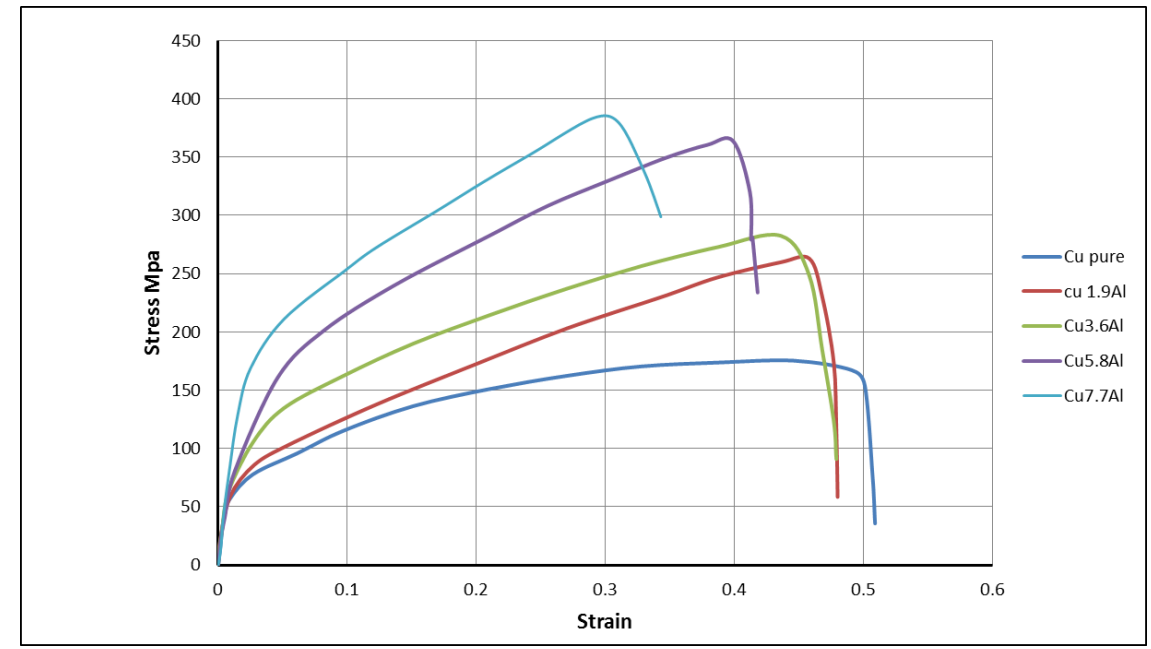

Figure 10: the stress-strain curves with $\mathrm{Al}$ content of $\mathrm{Cu}-\mathrm{Al}$ alloy that homogenized at $850{ }^{\circ} \mathrm{C}$ for 4 hours

This is due to the interactions of grain boundary strengthening, strain hardening, and obstacle the dislocation movement during the deformation that occurs in the tensile test. Avoiding the coarse precipitates and redistributing during solidification of the alloying elements is consider the main reason for the 


\section{AL-QADISIYAH JOURNAL FOR ENGINEERING SCIENCES}

Vol. 11, No. 2

ISSN: $1998-4456$

improvement of the mechanical properties of the alloy[22]. From Figure (11) the decrease in elongation from $21.42 \%$ to $11.19 \%$ was observed with an increase in $\mathrm{Al}$ from 1.9 to $3.9 \mathrm{wt} \%$ due to strain hardening. Whereas the percentage of elongation slightly increase from 11.19 to $26.90 \mathrm{wt} \%$ with an increase in Al from 3.9 to $7.7 \mathrm{wt} \%$ due to grain boundary sliding becomes the major deformation mechanism.

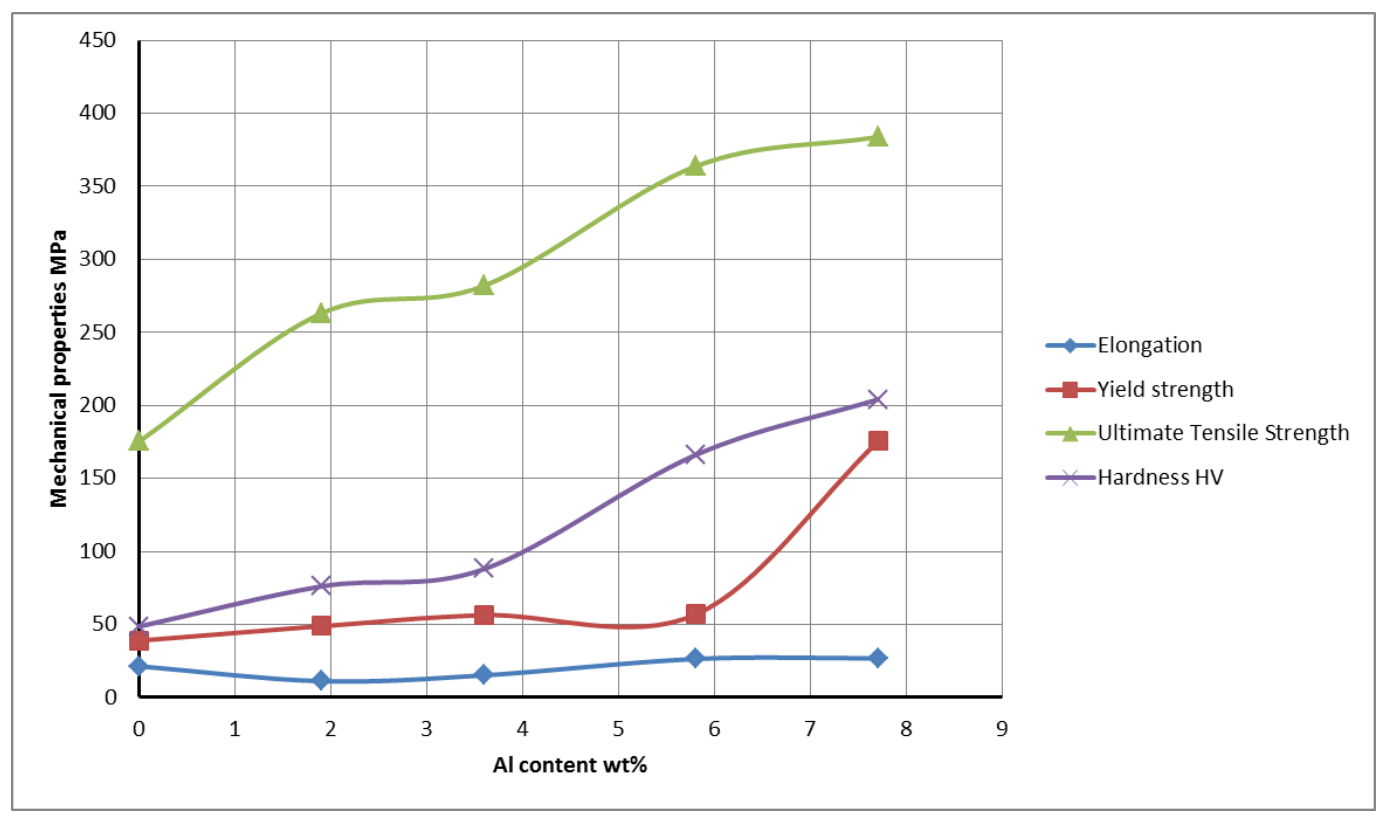

Figure 11: Ultimate Tensile Strength, yield strength, hardness and elongation with $\mathrm{Al}$ content of $\mathrm{Cu}-\mathrm{Al}$ alloy that homogenized at $850{ }^{\circ} \mathrm{C}$ for $4 \mathrm{hrs}$.

\section{CONCLUSIONS}

The effects of $\mathrm{Al}$ content and heat treatment on the mechanical properties of the Aluminum bronze alloy were investigated. The results showed changes in microstructure. The dendrites microstructure was changed to equiaxed grains that were formed after homogenization. These changes were contributed to improve in the mechanical properties such as ultimate tensile stress and yield stress whereas the elongation was slightly increased due to domination grain boundary sliding on the deformation mechanism. It also indicated that solid solution strengthening occurred owing to the increase in Al content. The increasing in Al content led to increase in hardness values of samples due to the formation of a solid solution phase that causes solid solution hardening. 


\section{REFERENCES}

1. Wang, Huang; and Xie, "Enhanced room-temperature tensile ductility of columnar-grained polycrystalline $\mathrm{Cu}-12 \mathrm{wt} . \% \mathrm{Al}$ alloy through texture control by Ohno continuous casting process," Materials Letters, vol. 65, 2011, pp.(1123-1126).

2. Zhang Werwen; Xia Wei, Wen Li-ping, WU Yuarr biao and Pan Guoru "Mechanical Properties and Tribological Behavior of a Cast Heat Resisting Copper Base Alloy" J.Cent. South Univ. TECHNO. (Journal CSUT). 9(4), 2003, pp. (235-239).

3. Rohatgi Vecchio; and Gray, "The influence of stacking fault energy on the mechanical behavior of $\mathrm{Cu}$ and $\mathrm{Cu}-\mathrm{Al}$ alloys: Deformation twinning, work hardening, and dynamic recovery," Metallurgical and Materials Transactions A, vol. 32, 2001, pp. (135-145).

4. Guofa; Jinzhi ZHANG, Sanlei LV2 and Ping WANG "The effect of aging heat treatment on the sliding wear behavior of Cu-Al-Fe-(x) alloys", Advanced Materials Research Vol. 20, 211 ,pp. (195201).

5. Gupta; Ghosh, "Choice Of Heat Treatment Mode For Increasing The Hardness of Cu-9\% AL-6\% Ni-5\% Fe Alloy" Metal Science and Heat Treatment Vol. 47, No.11 - 12, 2005, pp.(526-528).

6. Peter Sláma; Jaromír Dlouhý, Michal Kövér, "Influence of Heat Treatment on The Microstructure and Mechanical Properties of Aluminum Bronze" Materiali in tehnologije / Materials and technology 48, , 4, 2014, pp.(599-604).

7. Abdul Hameed Khan; Pravin Kumar Singh, "Influence Of Heat Treatment on Microstructure and Mechanical Properties of Aluminum Bronze" International Journal of Metallurgical \& Materials Science and Engineering (IJMMSE) Vol. 3, Issue 1, 2013, pp.(57-66).

8. Achitei Dragoş Cristian; VIZUREANU "Improvement of Properties of Aluminum Bronze CuAl7Mn3 by Heat Treatments" Applied Mechanics and Materials, Trans Tech Publications, Switzerland, 2014, pp. (1-2).

9. Chen; Dong; "Size Effects on Tensile Strength of Aluminum-Bronze Alloy At Room Temperature" Materials and Design 85, 2015, pp. (778-784).

10. Stephen Copley; "Heat Treating ASM Handbook" Volume 4, ASM Handbook Committee, 1991.

11. Sami Ajeel, Ahmed Ibrahiem, Abdul Salam Fadhil, "Study on Improvement of Casting Conditions for Some Aluminum Bronze Alloys", Eng. \& Technology, Vol.25, No.6, 2007, pp. (1-7).

12. Obi; Nnuka and Nnakwo; "Effect of Soaking Time and Quenching Media on the Structure and Mechanical Properties of Aluminium Bronze (Cu-10\%wt.Al)", IJSRSET, Volume 3 Issue 2, 2017, pp.(1-9). 
13. Rzadkosza, Kranc," Research on Technology of Alloyed Copper Casting" archives of foundry engineering volume 14,2014 , pp. (79-84).

14. ChengdongXia; Wan Zhang, "High strength and high electrical conductivity $\mathrm{Cu}-\mathrm{Cr}$ system alloys manufactured by hot rolling-quenching process and thermomechanical treatments" Materials Science and Engineering A 538, 2012, pp.(295-301).

15. Gavrilova; Petkov "Researches on the structure and properties of heat treated, nickel alloyed, molybdenum modified aluminum bronze", Bulgarian Chemical Communications, Volume 45, Number 4, 2013, pp. (644-648).

16. Matijević; Thota Surya Krishna Sushma, Prathv "Effect Of Heat Treatment Parameters On The Mechanical Properties And Microstructure Of Aluminium Bronze” TEHNIČKI GLASNIK 11, 3, 2017, pp.(107-110).

17. Abdul and Pravin "Influence of Heat Treatment on Microstructure and Mechanical Properties of Aluminum Bronze", International Journal of Metallurgical and Materials Science and Engineering (IJMMSE), 3, 2013 ,pp. (57-66).

18. Predescu; Vasile, Predescu, Sohaciu, Berbecaru, "Researches Regarding the Nature of the Embeddings in the Cast Pieces Made of Aluminium Alloys", Applied Mechanics and Materials. Volume 5, 2012, pp. (236-237).

19. Günter Joseph; Konrad Kundig "copper: Its Trade, Manufacture, Use, and Environmental Status" international copper associated ASM 2001, pp.(654-675).

20. Olofinjana; "Properties of rapidly solidified binary copper alloys" Materials Letters 3, 1997, pp (8792).

21. Bögel; "Stress relaxation in copper alloys for connectors and spring elements", metal (48) No. 11, 1994, p. (872-876).

22. Mohammad Baghani; Mahmood Aliofkhazraei; and Mehdi Askari, " $\mathrm{Cu}-\mathrm{Zn}-\mathrm{Al}_{2} \mathrm{O}_{3}$ nanocomposites: study of microstructure, corrosion, and wear" International Journal of Minerals, Metallurgy and Materials Volume 24, Number 4, 2017, pp.(324- 462). 